\title{
PARTICLE SIZE DISTRIBUTION OF RICE FLOUR AFFECTING THE STARCH ENZYMATIC HYDROLYSIS AND HYDRATION PROPERTIES
}

Esther de la Hera ${ }^{\mathrm{a}, \mathrm{b}}$, Manuel Gomez ${ }^{\mathrm{b}}$, Cristina M. Rosell ${ }^{\mathrm{a}}$

${ }^{a}$ Food Science Department, Institute of Agrochemistry and Food Technology (IATA-CSIC), Avenida Agustin Escardino, 7, Paterna 46980, Valencia, Spain

${ }^{\mathrm{b}}$ Food Technology Area, E.T.S. Ingenierías Agrarias. Valladolid University, Edificio La Yutera, Avenida Madrid, 44, 34004, Palencia, Spain.

*Corresponding author e-mail: crosell@iata.csic.es. Phone number +34 963900022. Fax number: +34963636301

Running title: Assessing impact of rice flour particle size heterogeneity 


\begin{abstract}
Rice flour is becoming very attractive as raw material, but there is lack of information about the influence of particle size on its functional properties and starch digestibility. This study evaluates the degree of dependence of the rice flour functional properties, mainly derived from starch behaviour, with the particle size distribution. Hydration properties of flours and gels and starch enzymatic hydrolysis of individual fractions were assessed. Particle size heterogeneity on rice flour significantly affected functional properties and starch features, at room temperature and also after gelatinization; and the extent of that effect was grain type dependent. Particle size heterogeneity on rice flour induces different pattern in starch enzymatic hydrolysis, with the long grain having slower hydrolysis as indicated the rate constant $(k)$.. No correlation between starch digestibility and hydration properties or the protein content was observed. It seems that in intact granules interactions with other grain components must be taken into account. Overall, particle size fractionation of rice flour might be advisable for selecting specific physicochemical properties.
\end{abstract}

Keywords: rice flour; particle size; starch damage; physical properties; starch hydrolysis

\title{
Highlights
}

- Particle size heterogeneity of rice flour affects hydration properties

- Rice flour hydration properties increase with the reduction of particle size

- Starch enzymatic hydrolysis varies with the particle size distribution

- There was not a clear relationship between particle size and starch hydrolysis rate 


\section{Introduction}

Rice varieties are mostly designated to be consumed as intact kernels, but lately a significant raise in the rice flour production is observed (FAOSTAT, 2012) due to its employment in novel foods such as baby and gluten-free based goods. Rice is mainly composed of starch (Champagne, Wood, Juliano \& Bechtel, 2006), which determines the eating quality of cooked rice (Moldenhauer, Gibbons \& McKenzie, 2006).

Rice grinding has been used as physical treatment to reduce particle size and obtain rice flour. However, although grinding is necessary to reduce particle size, it also entails damage to starch granules by the disruption of the granular structure (Level 5) of starch (Tran et al., 2011). The size of starch granules varies between non-waxy and waxy, long and short-grain rice starches and it also varies from cultivar to cultivar (Hoover, Sailaja \& Sosulski, 1996; Wani et al., 2012). Numerous studies have analysed the effect of mill type on the rice flour particle size distribution. Nishita and Bean (1982) were pioneers clarifying the impact of grinding methods on rice flour properties and later on, higher water binding capacity and swelling power were observed when intensifying milling (Perdon, Siebenmorgen, Mauromoustakos, Griffin \& Johnson, 2001). It seems that the range of particle size distribution is dependent on the mill used for grinding, and pin-milled and hammer-milled flours show the lowest granulation (Nishita \& Bean, 1982). Moreover, the heat exposure of rice during grinding could change flour characteristics, for example the content of starch damage. Hammer and roller - milled flours had the highest value of starch damage, besides the highest flour temperature after grinding. Kadan, Bryant and Miller (2008) investigated the characteristics of commercial long-rice flour ground in two steps with a hammer-mill and a turbo mill, stating that current methods used to make 
commercial rice flour do not produce uniform particle size. Particle size heterogeneity significantly affects the physico-chemical properties of the flours by increasing the surface area per volume unit and also it can increase the bioavailability of macronutrients (carbohydrate, proteins) by raising the rate of digestion which readily would affect human nutrition (Wondra, Hancock, Behnke, \& Stark, 1995). That fact has been confirmed in barley and sorghum flour in which the kinetic of starch digestion by alfa-amylase was dependent on the particle size of the flours (Al-Rabadi, Gilbert \& Gidley, 2009). Considering that nutrient distribution in grain fragments varies with particle size it is understandable and expected that their functionality and processing performance vary with the particle size. In fact, particle size fractionation by air classification or sieving has been proposed as strategy for adding value to coarsely milled grain like obtaining beta-glucan enriched fractions from barley milling stream (Sundberg, Tilly \& Aman, 1995). Despite the potential of that strategy only sorghum and barley have been targeted as cereals for improving digestibility and nutritional potential. Recently, de la Hera, Talegón, Caballero and Gómez (2012) stated the influence of particle size of corn flour on gluten free bread performance concluding that coarser flours $(>180 \mu \mathrm{m})$ provide breads with higher volume and softer crumbs due to their ability to retain carbon dioxide during proofing, whereas finer flours $(<106 \mu \mathrm{m})$ are more suitable for cakes (de la Hera, Martínez, Oliete \& Gómez, 2012).

In spite of the increasing consumption of rice flours, there are no studies focussed on the effect of particle size distribution on the physico-chemical properties and starch digestibility. Previous works characterized rice flour and checked the influence of particle size but focussing on flour obtained from different grinding methods. The aim of this research was to evaluate the degree of dependence of the rice flour functional properties, mainly derived from starch behaviour, with 
the particle size distribution of rice flour obtained by sieving, namely flour properties and starch features regarding enzymatic susceptibility. With that purpose two different rice cultivars were selected to determine the incidence of kernel hardness in those properties.

\section{Materials and methods}

\subsection{Materials}

Two rice grain types, one short and one long, were purchased from the local market and ground

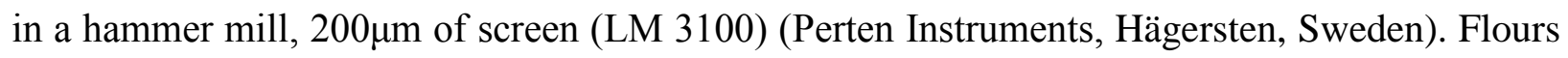
were sifted in a Bühler MLI 300B (Bühler AG, Uzwil, Switzerland) with screens of 80, 132, 150 and 180 microns during 15 minutes to obtain 5 fractions.

\subsection{Methods}

2.2.1. Particle size and protein determination

Flours were analyzed following AACC method (AACC, 2012) for protein (AACC, 46-30.01).

Determinations were carried out in duplicate. The particle size distribution was measured using a particle size analyzer with laser diffraction Helos \& Rodos (Sympatec, Clausthal-Zellerfeld, Germany). Short grain rice, fraction $<80 \mu \mathrm{m}$ (average $44 \mu \mathrm{m}$ ), 80-132 fraction (average $122 \mu \mathrm{m}$ ),

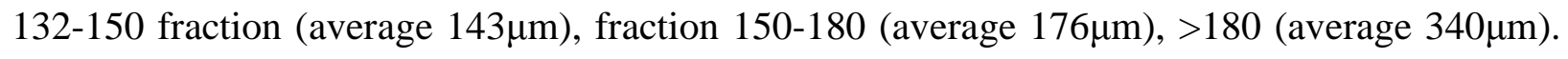
Long grain rice, fraction $<80 \mu \mathrm{m}$ (average $48.55 \mu \mathrm{m}$ ), 80-132 fraction (average $125 \mu \mathrm{m}$ ), 132-150 fraction (average 147 $\mu \mathrm{m}$ ), 150-180 fraction (average $171 \mu \mathrm{m}$ ), $>180$ (average $316 \mu \mathrm{m}$ ).

2.2.2. Determination of damaged starch content 
The starch damage content in the flour samples was determined in accordance with the AACC method (AACC, 2012), by using Megazyme starch damage kit (Megazyme International Ireland Ltd, Co. Wicklow, Ireland). Absorbance was read at $510 \mathrm{~nm}$ in a microplate reader BIOTEK EPOCH (Izasa, Barcelona, Spain). The starch damage was determined as percentage of flour weight on dry basis. Three replicates were made for each sample.

\subsubsection{Flour hydration properties}

The water holding capacity (WHC) defined as the amount of water retained by the sample without being subjected to any stress was determined mixing flour $(1.000 \mathrm{~g} \pm 0.005 \mathrm{~g})$ with distilled water $(10 \mathrm{ml})$ and kept at room temperature for $24 \mathrm{~h}$. The supernatant was decanted. WHC was expressed as grams of water retained per gram of solid.

The swelling volume was determined following the method reported by Gularte \& Rosell (2011) with slight modification. Samples $(1.000 \mathrm{~g} \pm 0.005 \mathrm{~g})$ were placed in a graduated cylinder and mixed with distilled water $(10 \mathrm{ml})$, then kept at room temperature for $24 \mathrm{~h}$. The swelling volume was calculated by dividing the total volume of the swollen sample and the original dry weight of the sample.

The water binding capacity (WBC) defined as the amount of water retained by the sample under low-speed centrifugation was determined as described the standard method (AACC, 2010). Samples $(1.000 \mathrm{~g} \pm 0.005 \mathrm{~g})$ were mixed with distilled water $(10 \mathrm{ml})$ and centrifuged at $2000 \mathrm{x} g$ for 10min. WBC was expressed as grams of water retained per gram of solid. Flour hydration properties were analyzed in triplicate.

For the determination of oil absorption capacity (OAC), the method of Lin, Humbert and Sosulski (1974) was followed. Briefly, rice flour $(100.0 \mathrm{mg} \pm 0.2 \mathrm{mg})$ was mixed with $1.0 \mathrm{ml}$ of 
vegetable oil. The content was stirred for 1 min with a wire rod to disperse the sample in the oil. After a period of $30 \mathrm{~min}$ in the vortex mixer, tubes were centrifuged at $3000 \mathrm{x} g$ and $4^{\circ} \mathrm{C}$ for 10 min. The supernatant was carefully removed with a pipette and tubes were inverted for $25 \mathrm{~min}$ to drain the oil and the residue weighed (Wr). The oil absorption capacity was expressed as grams of oil bound per gram of the sample on dry basis. Three replicates were made for each sample. OAC was calculated by the equation 1 :

OAC $(g / g)=$ Wr $/$ Wi Eq. 1

where Wi was the sample weight (g, db).

\subsubsection{Gel hydration properties}

Water absorption index (WAI) or swelling capacity and water solubility index (WSI) of different rice flour fractions were determined following the method of Toyokawa, Rubenthaler, Powers, and Schanus (1989), with slight modification as reported Rosell, Yokoyama \& Shoemaker (2011). Briefly, flour (50.0mg $\pm 0.1 \mathrm{mg}$ ) sample was dispersed in $1.0 \mathrm{ml}$ of distilled water in an eppendorf tube using a wire rod and cooked at $90{ }^{\circ} \mathrm{C}$ for $10 \mathrm{~min}$ in a water bath. The cooked paste was cooled in an ice water bath for $10 \mathrm{~min}$, and then centrifuged at $3000 \mathrm{x} g$ at $4^{\circ} \mathrm{C}$ for 10 min. The supernatant was decanted into an evaporating dish and the weight of dry solids was recovered by evaporating the supernatant at $105{ }^{\circ} \mathrm{C}$ till constant weight. Four replicates were made for each sample. Residues (Wr) and dried supernatants (Ws) were weighed and WSI or swelling capacity, solubility index and swelling power (SP) were calculated as follows: 
$\mathrm{WAI}(\mathrm{g} / \mathrm{g})=\mathrm{Wr} / \mathrm{Wi} \quad$ Eq. 2

WSI $(g / 100 g)=(W s / W i) \times 100 \quad$ Eq. 3

$\mathrm{SP}(\mathrm{g} / \mathrm{g})=\mathrm{Wr} /(\mathrm{Wi}-\mathrm{Ws}) \quad$ Eq. 4

where Wi was the sample weight (g, db).

Values were the average from four replicates.

\subsubsection{Amylose/amylopectin ratio}

A change in the composition of linear or branched fractions of starch can be indicated by a change in the ratio of absorbance of iodine starch complexes at 630 and $520 \mathrm{~nm}$ (Sokhey \& Chinnaswamy, 1992). The ratio of amylose/amylopectin was determined following the method described by Gujral and Rosell (2004). Rice flour fraction (50.0mg $\pm 0.1 \mathrm{mg}$ ) was dispersed in $1.0 \mathrm{ml}$ of distilled water in an eppendorf tube using a wire rod and cooked at $90{ }^{\circ} \mathrm{C}$ for $15 \mathrm{~min}$ in a water bath. The cooked paste was cooled in ice water bath to room temperature, and then centrifuged at $3000 \mathrm{xg}$ at $4^{\circ} \mathrm{C}$ for $10 \mathrm{~min}$. After removing the supernatant, the pasted samples were defatted with methanol and 20mg of defatted sample were extracted with $1 \mathrm{M} \mathrm{KOH}$ for 2 min and centrifuged for $5 \mathrm{~min}$ at $16000 \times \mathrm{g}$. To $250 \mu \mathrm{l}$ of the supernatant, $1.0 \mathrm{ml}$ of Lugol's iodine solution ( $2 \mathrm{~g}$ potassium iodide and $1.3 \mathrm{~g}$ of iodine in $100 \mathrm{ml}$ distilled water), and water $(7.5 \mathrm{ml})$ were added and then neutralized with $1 \mathrm{M} \mathrm{HCl}$. The solution was further diluted 10 times and absorbance measured at 630 and 520nm for amylose and amylopectin determination, respectively. Four replicates were performed for each sample. 


\subsubsection{Enzymatic starch hydrolysis}

Starch hydrolysis was measured following the method described by Gularte and Rosell (2011) with minor modifications. Briefly, for free sugars removal, flour sample $(0.1 \mathrm{~g})$ suspended in two milliliters of $80 \%$ ethanol was kept in a shaking water bath at $85^{\circ} \mathrm{C}$ for five minutes, and then centrifuged for 10 min at $1000 \times g$. The pellet was incubated with porcine pancreatic $\alpha$ amylase (10 mg/ml) (Type VI-B, $\geq 10$ units/mg solid, Sigma Chemical, St. Louis, USA) and amyloglucosidase (3300 U/ml) (Sigma Chemical, St. Louis, USA) in $10 \mathrm{ml}$ of $0.1 \mathrm{M}$ sodium maleate buffer ( $\mathrm{pH}$ 6.0) in a shaking water bath at $37^{\circ} \mathrm{C}(0.25-16 \mathrm{~h})$. Aliquots of $200 \mu \mathrm{l}$ were withdrawn during the incubation period. Aliquots were mixed with $200 \mu \mathrm{l}$ of ethanol (96\%) to stop the enzymatic reaction and the sample was centrifuged for $5 \mathrm{~min}$ at $10000 \times g$ and $4{ }^{\circ} \mathrm{C}$. The precipitate was washed twice with $50 \%$ ethanol $(100 \mu \mathrm{l})$ and the supernatants were pooled together and kept at $4{ }^{\circ} \mathrm{C}$ for further glucose determination.

The remnant starch after 16 h hydrolysis was solubilized with $2 \mathrm{ml}$ of $2 \mathrm{M} \mathrm{KOH}$ using a Polytron ultraturrax homogenizer IKA-T18 (IKA works, Wilmington, USA) during 1min at speed 3. The homogenate was diluted with $8 \mathrm{ml} 1.2 \mathrm{M}$ sodium acetate $\mathrm{pH} 3.8$ and incubated with $100 \mu \mathrm{l}$ amyloglucosidase (3300 U) at $50{ }^{\circ} \mathrm{C}$ for $30 \mathrm{~min}$ in a shaking water bath. After centrifuging at $2000 \times g$ for $10 \mathrm{~min}$, supernatant was kept for glucose determination.

The glucose content was measured using a glucose oxidase-peroxidase (GOPOD) kit. The absorbance was measured using an Epoch microplate reader (Biotek Instruments, Winooski, USA) at $510 \mathrm{~nm}$. Starch was calculated as glucose $(\mathrm{mg}) \times 0.9$. Replicates $(\mathrm{n}=2-4)$ were carried out for each determination. 
Experimental data were fitted to a first-order equation (Goñi et al., 1997):

$C_{t}=C_{\infty}\left(1-\mathrm{e}^{-k t}\right) \quad$ Eq. 5

Where $C_{t}$ is the concentration of product at time $t, C_{\infty}$ is the concentration at the end point, and $k$ is the pseudo-first order rate constant. Although this equation requires the estimation of an accurate $C_{\infty}$, it was useful because long reaction times were applied to determine resistant starch after complete enzymatic hydrolysis. The plot of $\ln \left[\left(C_{\infty}-C_{t}\right) / C_{\infty}\right]=-k t$ against $t$ was used to estimate the slope that corresponded to $-k$.

However, as recently suggested Butterworth, Warren, Grassby, Patel and Ellis (2012), the linear plot of $\ln (\mathrm{d} C / \mathrm{d} t)$ against $t$ was also represented to calculate the slope $(-k)$, and the intercept on the $y$ axis was used for calculating the $\ln \left(k C_{\infty}\right)$. This plot was used to demonstrate if the data were of logarithmic form and the rate constant remained unchanged along the whole hydrolysis reaction, as recommended Poulsen, Ruiter, Wisser, Jorgen and Iversen (2003).

\subsubsection{Statistical analysis}

Data were subjected to an analysis of variance (ANOVA) considering the flours individually, in order to study the differences between flours. Fisher's least significant difference (LSD) test was used to describe means with 95\% confidence. A correlation analysis was also carried out. Statgraphics Plus V5.1 (Statpoint Technologies, Warrenton, USA) was used as statistical analysis software.

\section{Results and Discussion}

3.1. Protein content, ratio of amylose/amylopectin and damage starch 
Rice flours from two different grain types were sifted into five different particle size fractions (Table 1). Two types of rice grains were selected due to their diverse properties greatly attributed to variations in the amylose content (de la Hera et al., 2012). Protein content and the ratio of amylose/amylopectin of the fractions were determined to identify a possible trend with the particle size. The smallest particle size in both grains showed the lowest protein content. Furthermore, a steady increase of the protein content was observed when enhancing the particle size up to $180 \mu \mathrm{m}$ (Table 1). The highest particle size fraction from both grain types did not follow that trend. Likely, there is a critical point for affecting the molecular distribution of the grain components during milling. This distribution could be due to the allocation of protein during milling. Protein concentration is higher on the surface of milled rice and decreases toward the center of the kernel (Champagne et al., 2006). Therefore, harder and more vitreous zones in the kernel would result in coarser particles which, in this case would have greater protein content. Regarding the grain type, in the samples tested the protein content was significantly higher in the fractions from short rice grain compared to their counterparts from long rice grain.

The ratio of amylose/amylopectin for each fraction of both rice grain types is shown in Table 1. A change in the ratio of absorbance of iodine starch complexes at 630 and $520 \mathrm{~nm}$, for amylose and amylopectin, respectively, indicates a change in the composition of linear or branched fractions of starch molecules. With the exception of the smallest particle size fraction $(<80 \mu \mathrm{m})$, fractions from long rice grain showed significantly higher amylose/amylopectin ratio than their counterparts from short grains, indicating higher amylose content on those fractions, which agree with previous findings (Qin-lu et al., 2011). Regarding the particle size, no general trend could be observed, but it seems that low amylose content was present in fractions with particles 
size ranged from $150 \mu \mathrm{m}$ to $180 \mu \mathrm{m}$, which, as was mentioned above contained higher amount of proteins.

The incidence of particle size heterogeneity on starch damage is shown in Table 1. Fractions from short rice grain showed a steady decrease of the starch damage whilst particle size diminished. Conversely, that trend was not evident within the fractions from long rice grain, only the coarsest fraction showed significantly higher amount of starch damage than the smallest fraction. Fractions from short grain rice displayed greater values of starch damage than their counterparts from long grain. Hasjim, Li \& Dhital (2012) observed a positive relationship between the amount of starch damage and the decrease in the opening size up to $132 \mu \mathrm{m}$ of hammer mill screen when studied long grain rice, and no relationship was observed with smaller particle size. Those authors forced the particle size reduction by modifying milling force, time or screen size, promoting starch damage as particle size reduces. However, it seems that a different picture is obtained when studied the properties of particle size heterogeneity, above all fractions from short grain rice. When no differences in milling process exist, starch damage changes pertaining particle size heterogeneity must be explained by structural modifications in the grain. Considering the hierarchical levels defined to explain the structural organization of the cereal starches that comprise individual linear branches of starch (Level 1), whole branched molecules (Level 2), semi-crystalline lamellae (Level 3), growth rings (Level 4), individual starch granules (Level 5), and starch granules interacting with protein and cell-wall matrices (Level 6) (Tran et al., 2011), the physical injury of the starch granules that facilitate the enzyme's accessibility would be related to the breakage of Level 5 of starch structure with great contribution of the Level 6. 


\subsection{Hydration properties of rice flour fractions}

Hydration properties were significantly affected with the particle size heterogeneity (Table 2), and that effect was observed in both types of flours, although in general, fractions from short rice grain showed greater changes. In fact, WHC increased with decreasing the particle size of the rice flour, but in long grain rice only significant differences where observed with the smallest particle size fraction. It seems that a reduction in particle size resulted in no effect (long grain) or steady increase (short grain) of WHC up to a critical size $(<80)$, after which further reduction of size induced stronger effect attributable to molecular and structural changes of grain components. A significant negative correlation was obtained between the particle size and the WHC ( $r=-0.7574, P<0.01)$. These results were expected, considering that greater surface area is exposed to water molecules binding in fine particles, inducing higher water intake. Swelling also showed significant increase when reducing the particle size of the fraction $(r=-0.8579$, $P<0.01)$ in both rice grain flours.

Water binding capacity values increased with the decrease in the opening size of sieves in both grain types $(r=-0.7557, P<0.01)$. Comparing grain types, long grain fractions showed higher water binding capacity than short grain counterpart fractions. Probably, internal structure of long grain (more vitreous than short grain) strongly retains the absorbed water under stress conditions. A negative significant correlation was observed between WBC and the protein content $(r=-0.7790, P<0.01)$, amylose/amylopectin ratio $(r=-0.7983, P<0.01)$ and starch damage ( $r=-0.7287, P<0.001)$. Farrand (1972) affirmed that undamaged starch absorbs only $30 \%$ water at $30^{\circ} \mathrm{C}$, but damaged starch absorbs its own weight of water at $30^{\circ} \mathrm{C}$. Nevertheless, it seems that differences observed in the amount of starch damage in the different fractions were not large 
enough to compensate differences on the hydration properties attributed to the increased surface area in line with reduced particle size. Hence, it could be said that physical properties, particle size in this case, prevail over chemical composition (starch damage and protein content), and likely interactions between starch and non-starch components affected hydration properties.

Oil absorption capacity was determined to measure the ability of the flour protein to physically bind fat by capillary attraction. OAC values ranged from $0.556 \mathrm{~g} / \mathrm{g}$ to $0.784 \mathrm{~g} / \mathrm{g}$, increasing while particle size decreased in short and long rice flours $(r=-0.7827, P<0.01)$. Barely differences were distinguished due to the type of rice grain. OAC showed an inverse significant correlation with proteins $(r=-0.7958, P<0.01)$. It seems that particle size had large influence on the oil absorption capacity. Probably, the force applied during milling and the sieving process affected molecularly the starch and proteins as occurred with cell wall components, that decrease their abilities to bind water and oil (Mahasukhonthachat, Sopade \& Gidley, 2010), enhancing the significance of particle size in these processes of absorption.

\subsection{Gel hydration properties}

Water uptake during thermal treatment, which involves starch gelatinization and protein denaturation, was assessed by determining the water absorption index or swelling capacity and swelling powder (Table 3). The water absorption index was hardly affected by the particle size, with the exception of the smallest fraction that showed lower WAI, although the difference was only significant for the short grain. The same tendency was observed in the swelling powder of the different fractions. Presumably, the level of starch damage besides the interactions with nonstarch components like proteins and cell walls matrices affected the water uptake ability. Kadan, 
Bryant and Miller (2008) also observed no differences in WAI of rice flours, obtained by different grinding methods (pin mill and Udy), having particle size distribution over $100 \mu \mathrm{m}$. Similar studies carried out with sorghum concluded that particle size seems to be less important than milling type regarding WAI (Mahasukhonthachat et al., 2010). It must be pointed out that in those studies the smallest screen used was of $100 \mu \mathrm{m}$ openings, but very fine particles (under $100 \mu \mathrm{m})$ seem to display different gel hydration behavior. In fact, it has been reported that a reduction in the particle size of barley was accompanied by a reduction in the water retention capacity, presumably due to the breakdown of cellular structures by milling, leading to the collapse of the cell wall matrix (Anguita, Gasa, Martin-Orue \& Perez, 2006). In addition, the level of amylose has been related to the swelling power of rice and achira starches (Chung, Liu, Lee \& Wei, 2011; Andrade-Mahecha Tapia-Blacido, \& Menegalli, 2012). Swelling is primarily an amylopectin property and the amylose is mainly inhibiting it (Tester \& Morrison, 1990) but it seems that the presence of the other non-starch components affects the swelling pattern of amylopectin and its ability to swell might be hindered by the other structural constituents.

Water solubility index showed erratic behaviour in both short and long grain. WSI in short grain did not show significant differences among fractions, neither in long grain type. Initially, it should not expect that particle size heterogeneity influences the distributions of soluble solids, and results seems to confirm it. Same results were observed with sorghum and barley, where no relationship was observed between particle size distribution lower than $250 \mu \mathrm{m}$ and their water solubility index (Al-Rabadi et al., 2012). Nevertheless, when experimental results were pooled together, it was observed a positive relationship between the amylose/amylopectin ratio and the 
water solubility index $(r=0.8165, P<0.001)$, likely due to the amylose leached out during heating.

\subsection{Starch enzymatic hydrolysis}

Intact starch granules offer great resistance to enzymatic hydrolysis, thus the possible damage suffered by starch granules due to mechanical process should be clearly visible in the kinetic of enzymatic hydrolysis. The fraction of starch which undergoes limited enzymatic hydrolysis is termed resistant starch (RS).

The amount of resistant starch was below $4 \%$ in all the flour fractions, and no correlation was observed with the particle size and neither with the type of grain (Table 4). The starch hydrolysis curves for short and long grain flours are showed in Figure 1. It was really evident that fractions from long grain rice underwent lower enzymatic hydrolysis, indicating minor susceptibility to enzymes attack, likely attributable to amylose content differences. Chung et al (2011) reported lower amount of rapidly digestible starch fraction in the rice starches from long grain which was explained due to the high amylose content since amylose in starch granules was resistant to digestion by enzymes. Differences among enzymatic hydrolysis plots of flour fractions from short grain were largely noticeable when particle size was higher than $150 \mu \mathrm{m}$, displaying slower hydrolysis when increasing the particle size. Conversely, fractions from long grain showed differences with particle size distribution but without any direct relationship with the particle size. The slowest hydrolysis was detected for the range $132 \mu \mathrm{m}-150 \mu \mathrm{m}$ particle size in the long type rice. Below that particle size it was observed lower hydrolysis with the reduction of particle size and the opposite was detected with particles bigger than $150 \mu \mathrm{m}$. It has been 
reported that alfa-amylase affinity for native starches is dependent on the particle size of starch, due to the enzyme feasibility for binding/absorption (Tahir et al., 2010). As particle size decreases, the surface area exposed to digestive enzymes increases, leading to an increased rate of digestion (Bjorck et al., 1994; Pi-Sunyer, 2002). When assessing the starch granules susceptibility to enzyme hydrolysis is reported that the surface area of granules and the degree of order of starch have important influences on the initial rate at which native starch is digested by amylase (Tahir, Ellis \& Butterworth, 2010). Present results indicate that having the same size starches, the rest of the flour constituents are affecting the hydrolysis rate. Starch hydrolysis curves were plotted to obtain the rate constant fitting the values to a first-order equation and also to LOS plots. Table 4 shows that the rate constants estimated by the first order model agree well with the LOS plots, which is in agreement with the results showed by Butterworth et al (2012) when determined the rate constants of different foods or starches. Plots' results indicated that samples consisted of unique population regarding the rate of hydrolysis. The rate constants confirmed that long grain underwent slower hydrolysis than samples from short grains. Considering the degree of starch damage in each type of grain, it seems that diffusion of enzymes through the starch granule was not the rate-limiting factor, since no relationship was observed between them; neither differences encountered in the protein content. Differences in the content of protein associated to the starch granule surface could influence the accessibility of the alfa amylase but no relationship could be established between the protein content and the rate constants. Tester and Karkalas (2006) described that the larger granules the smaller is the surface area to volume ratio and hence the potential surface to be attacked and hydrolyzed by enzymes. However, that rule is not always followed or it could be that there existed a critical particle size beyond which the particle size would be no longer affecting the starch hydrolysis 
rate. It occurred with sorghum in vitro starch digestibility, where no significant differences were observed in the amount of starch hydrolyzed in flour particles lower than $250 \mu \mathrm{m}$ and larger particles showed a steady decrease in starch digestibility associated to a reduction in the surface area exposed to enzymatic attack (Al-Rabadi et al., 2012). Nevertheless, Mahaoukhonthachat et al. (2010) reported that in vitro digestion of cryo-milled sorghum follows first-order kinetics irrespective of the average particle size from $120 \mu \mathrm{m}$ to $560 \mu \mathrm{m}$ and the dependence of the digestion kinetics with the particle size was more accentuated by particle size below $270 \mu \mathrm{m}$. Presumably, differences in the range of particle size could be ascribed to the higher frictional heat induced by hammer mill compared to cryomills (Ngamnikom \& Songsermpong, 2011). Table 4 also displayed the values for $C_{\infty}$ experimentally obtained and the ones estimated from LOS plots. Again, results agree very well when using different equations for fitting the data. Divergences were observed in the fractions with higher particle size $(>180 \mu \mathrm{m})$ and those with particle size comprised between 132-150 $\mu \mathrm{m}$. Very good agreement was observed by Butterworth et al (2012) when compared different foods and starches. Different trend of $C_{\infty}$ was observed in the two types of grains. In the short grain, fractions with particle size higher than $132 \mu \mathrm{m}$ showed a progressive reduction in the $C_{\infty}$ with the increase in the particle size; whereas no variation in this parameter was observed at lower particle size. Conversely, in long grain only the highest particle size fraction showed significant higher $C_{\infty}$.

Significant relationships were observed between the hydration properties and the enzymatic hydrolysis parameters, particularly between the constant rate from the pseudo-first order plot and the WHC ( $r=0.6341, P<0.05)$ and swelling $(r=0.6679, P<0.05)$. The same was observed with the constant rate obtained from the LOS plots. This relationship could be easily understood 
considering that enzyme diffusion and accessibility within the starch granule surface, which likely follows the same interstitial places than water molecules.

\section{Conclusion}

Particle size heterogeneity on rice flour significantly affects functional properties and starch features, at room temperature and also after gelatinization; and the extent of that effect is grain type dependent. Generally, rice flour hydration properties increase with the reduction of particle size, but results suggest that there is a critical size $(<80)$, after which further reduction of size induced stronger effect attributable to molecular and structural changes of grain components. Hence, hydration properties are significantly dependent on particle size distribution besides the interactions between starch and non-starch components. Particularly, a significant negative correlation was obtained between the particle size and the WHC ( $r=-0.7574, P<0.01)$, swelling ( $r=-0.8579, P<0.01)$, water binding capacity $(r=-0.7557, P<0.01)$, and OAC $(r=-0.7827$, $P<0.01)$. These results were expected, considering that greater surface area is exposed to water molecules binding in fine particles, inducing higher water intake. Regarding the constituents of the flour, a negative significant correlation was observed between WBC and the protein content $(r=-0.7790, P<0.01)$ and starch damage $(r=-0.7287, P<0.001)$. OAC showed an inverse significant correlation with proteins $(r=-0.7958, P<0.01)$. Particle size heterogeneity on rice flour induces different pattern in starch enzymatic hydrolysis, which was grain type dependent. Long grain rice underwent lower enzymatic hydrolysis, indicating minor susceptibility to enzymes attack. 
When trying to understand the correlation between physical properties and enzyme susceptibility of the starch granules, significant relationships were observed between the hydration properties and the enzymatic hydrolysis parameters, particularly between the constant rate from the pseudo-first order plot and the WHC $(r=0.6341, \mathrm{P}<0.05)$ and swelling $(\mathrm{r}=0.6679, \mathrm{P}<0.05)$. It seems that in intact granules, there is no a clear relationship between particle size and hydrolysis rate, some other factors like interactions with other grain components must be taken into account. The unique significant relationships were observed between the amylose/amylopectin ratio and the constant rate therefore the lower susceptibility to enzymes attack of long grain rice might be attributable to amylose content differences. Considering the degree of starch damage in each type of grain, it seems that diffusion of enzymes through the starch granule was not the rate-limiting factor, since no relationship was observed between them; neither differences encountered in the protein content. Nevertheless, further studies will be undertaken to go deeper in the structure of the rice starch for explaining its hydrolysis behavior.

\section{Acknowledgements}

Authors acknowledge the financial support of the Spanish Ministry of Economy and Sustainability (Project AGL2011-23802), the European Regional Development Fund (FEDER) and Generalitat Valenciana (Project Prometeo 2012/064).

\section{References}

Al-Rabadi, G.J., Gilbert, R.G., \& Gidley, M.J. (2009). Effect of particle size on kinetics of starch digestion in milled barley and sorghum grains by porcine alpha-amylase. Journal of Cereal Science, 50, 198-204. 
Al-Rabadi, G.J., Torley, P.J., Williams, B.A., Bryden, W.L., \& Gidley, M.J. (2012). Particle size heterogeneity in milled barley and sorghum grains: Effects on physic-chemical properties and starch digestibility. Journal of Cereal Science, 56, 396-403.

American Association of Cereal Chemists, Approved Methods of Analysis, 11th edition. Methods: 46-30.01 (protein), 76-31.01 (damaged starch), 56-30.01 (WBC). American Association of Cereal Chemists, St Paul, MN (2012).

Andrade-Mahecha, M.M., Tapia-Blacido, D.R., \& Menegalli, F.C. (2012). Physical-chemical, thermal, and functional properties of achira (Canna indica L.) flour and starch from different geographical origin. Starch/Starke, 64, 348-358.

Anguita, M., Gasa, J., Martin-Orue, S.M., \& Perez, J.F. (2006). Study of the effect of technological processes on starch hydrolysis, non-starch polysaccharides solubilization and physicochemical properties of different ingredients using a two step in vitro system. Animal Feed Science Technology, 129, 99-115.

Bjorck, I., Granfeldt, Y., Liljeberg, H., Tovar, J., \& Asp, N. (1994). Food properties affecting the digestion and absorption of carbohydrates. American Journal of Clinical Nutrition, 59(Suppl), 699-705.

Butterworth, P.J., Warren, F.J., Grassby, T., Patel, H., \& Ellis, P.R. (2012). Analysis of starch amylolysis using plots for first-order kinetics. Carbohydrate Polymers, 87, 2189-2197.

Champagne, E.T., Wood, D.F., Juliano, B.O., \& Bechtel, D.B. (2006). The rice grain and its gross composition. In Champagne, E.T. (Ed.), Rice chemistry and technology, 3th Ed. American Association of Cereal Chemists, St. Paul, Minnesota, USA, pp. 77-108. 
Chung, H.J., Liu, Q., Lee, L., \& Wei, D. (2011). Relationships between the structure, physicochemical properties and in vitro digestibility of rice starches with different amylose content. Food Hydrocolloids, 25, 968-975.

FAOSTAT. (2012). Database of Food and Agricultural Organization. Available from www.faostat.fao.org. Accesed July 2012.

Farrand, E. A. (1972). The influence of particle size and starch damage on the characteristics of bread flours. Baker's Digest, 46(1), 22-26.

Goñi, I., Garcia-Alonso, A. \& Saura-Calixto, F. (1997). A starch hydrolysis procedure to estimate glycemic index. Nutrition Research, 17, 427-437.

Gularte, M.A., \& Rosell, C.M. (2011). Physicochemical properties and enzymatic hydrolysis of different starches in the presence of hydrocolloids. Carbohydrate Polymers, 85, 237-244.

Gujral, H., \& Rosell, C.M. (2004). Modification of the pasting properties of wheat starch by cyclodextrin glycosyltransferase. Journal of Science of Food and Agriculture, 84, 1685-1690.

Hasjim, J., Li, E., \& Dhital, S. (2012). Milling of rice grains: The roles of starch structures in the solubility and swelling properties of rice flour. Starch, 64, 631-645

de la Hera, E., Talegón, M., Caballero, P., \& Gómez, M. (2012). Influence of maize flour particle size on gluten free breadmaking. Journal of Science of Food and Agriculture, DOI 10.1002/jsfa.5826.

de la Hera, E., Martínez, M., Oliete, B., \& Gómez, M. (2012). Influence of flour particle size on quality of gluten-free rice cakes. Food Bioprocess Technology, DOI 10.1007/s11947-012-09226.

Hoover, R., Sailaja, Y., \& Sosulski, F.W. (1996). Characterization of starches from wild and long grain brown rice. Food Research International, 29(2), 99-107. 
Kadan, R.S., Bryant, R.J., \& Miller, J.A. (2008). Effects of milling on functional properties of rice flour. Journal of Food Science, 73 (4), 151-154.

Lee, K., Ryu, M., Kim, M., Kang, W., Ko, S., Shin, M., \& Chung, H. (2011). A comparative study of submicron- and micron-sized rice particles: enzymatic hydrolysis in vitro and food efficiency ratio in vivo. International Journal of Food Science and Technology, 46, 372378.Lin, M. J. Y., Humbert, E. S., \& Sosulski, F. W. (1974). Certain functional properties of sunflower meal products. Journal of Food Science, 39(2), 368-370.

Mahasukhonthachat, K., Sopade, P.A., \& Gidley, M.J. (2010). Kinetics of starch digestion in sorghum as affected by particle size. Journal of Food Engineering, 96, 18-28.

Moldenhauer, K.A.K., Gibbons, J.H., \& McKenzie, K.S. (2006). Rice varieties. In Champagne, E.T. (Ed.), Rice chemistry and technology, 3th Ed. American Association of Cereal Chemists, St. Paul, Minnesota, USA, pp. 49-76.

Ngamnikom, P., \& Songsermpong, S. (2011). The effects of freeze, dry, and wet grinding processes on rice flour properties and their energy consumption. Journal of Food Engineering. 104, 632-638.

Nishita, K. D., \& Bean, M. M. (1982). Grinding methods: Their impact on rice flour properties. Cereal Chemistry, 59, 46-49.

Perdon, A.A., Siebenmorgen, T.J., Mauromoustakos, A., Griffin, V.K., \& Johnson, E.R. (2001). Degree of milling effects on rice pasting properties. Cereal Chemistry, 78(2), 205-209

Pi-Sunyer, F.X. (2002). Glycemic index and disease. American Journal of Clinical Nutrition, 76(Suppl), 290-298. 
Poulsen, B. R., Ruiter, G., Visser, J., Jorgen, J. \& Iversen, J. J. L. (2003). Determination of first order rate constants by natural logarithm of the slope plot exemplified by analysis of Aspergillus niger in batch culture. Biotechnology Letters, 25, 565-571.

Qin-lu, L., Hua-xi, X., Xiang-jin, F., Wei, T., Li-hui, L., \& Feng-xiang, Y. (2011). Physicochemical properties of flour, starch, and modified starch of two rice varieties. Agricultural Sciences in China, 10(6), 960-968.

Rosell, C.M., Yokoyama, W., \& Shoemaker, C. (2011). Rheology of different hydrocolloids rice starch blends. Effect of successive heating-cooling cycles. Carbohydrate Polymers, 84, 373382.

Sokhey, A.S., \& Chinnaswamy, R. (1992). Physicochemical properties of irradiation modified starch extrudates. Food Structure, 11, 361-371.

Sundberg, B., Tilly, A.C., \& Aman, P. (1995). Enrichment of mixed-linked (1-3), (1-4)- beta-Dglucans from a high-fiber barley-milling stream by air classification and stack-sieving. Journal of Cereal Science, 21, 205-208.

Tahir, R., Ellis, P.R., \& Butterworth, P.J. (2010). The relation of physical properties of native starch granules to the kinetics of amylolysis catalysed by porcine pancreatic $\alpha$-amylase. Carbohydrate Polymers, 81, 57-62.

Tester, R.F., \& MorrisonW.R. (1990). Swelling and gelatinization of cereal starches. I. Effects of amylopectin, amylose and lipids. Cereal Chemistry, 67, 551-559.

Tester, R.F., \& Karkalas, J. (2006). Hydrolysis of native starches with amylases. Animal Feed Science and Technology, 130, 39-54.

Toyokawa, H., Rubenthaler, G. L., Powers, J. R., \& Schanus, E. G. (1989). Japanese noodle qualities. I. Flour components. Cereal Chemistry, 66, 382-386. 
Tran, T. B., Shelat, K.J., Tang, D., Li, E., Gilbert, R.G., \& Hasjim, J. (2011). Milling of rice grains. The degradation on three structural levels of starch in rice flour can be independently controlled during grinding. Journal of Agricultural and Food Chemistry, 59(8), 3964-3973.

Wani, A. A., Singh, P., Shah, M. A., Schweiggert-Weisz, U., Gul, K., \& Wani, I. A. (2012). Rice starch diversity: effects on structural, morphological, thermal, and physicochemical properties-A review. Comprehensive Reviews in Food Science and Food Safety, 11, 417-436.

Wondra, K.J., Hancock, J.D., Behnke, K.C., \& Stark, C.R. (1995). Effects of mill type and particle-size uniformity on growth-performance, nutrient digestibility, and stomach morphology in finishing pigs. Journal of Animal Science, 73, 2564-2573.

Zhu, L.J., Liu, Q.Q., Wilson, J.D., Gu, M.H. \& Shi, Y.C. (2011) Digestibility and physicochemical properties of rice (Oryza sativa L.) flours and starches differing in amylose content. Carbohydrate Polymers, 86, 1751-1759. 


\section{FIGURE CAPTIONS}

Figure 1. Effect of particle size distribution on the enzymatic starch hydrolysis kinetics. A) short grain rice and $\mathrm{B}$ ) long grain rice. 